\title{
Cocaine Experience Controls Bidirectional Synaptic Plasticity in the Nucleus Accumbens
}

\author{
Saïd Kourrich, ${ }^{1}$ Patrick E. Rothwell, ${ }^{1,2}$ Jason R. Klug, ${ }^{1}$ and Mark J. Thomas ${ }^{1,2}$ \\ ${ }^{1}$ Departments of Neuroscience and Psychology and Institute of Human Genetics, and ${ }^{2}$ Graduate Program in Neuroscience, University of Minnesota, \\ Minneapolis, Minnesota 55455
}

\begin{abstract}
Plasticity of glutamatergic synapses is a fundamental mechanism through which experience changes neural function to impact future behavior. In animal models of addiction, glutamatergic signaling in the nucleus accumbens (NAc) exerts powerful control over drugseeking behavior. However, little is known about whether, how or when experience with drugs may trigger synaptic plasticity in this key nucleus. Using whole-cell synaptic physiology in NAc brain slices, we demonstrate that a progression of bidirectional changes in glutamatergic synaptic strength occurs after repeated in vivo exposure to cocaine. During a protracted drug-free period, NAc neurons from cocaine-experienced mice develop a robust potentiation of AMPAR-mediated synaptic transmission. However, a single re-exposure to cocaine during extended withdrawal becomes a potent stimulus for synaptic depression, abruptly reversing the initial potentiation. These enduring modifications in AMPAR-mediated responses and plasticity may provide a neural substrate for disrupted processing of drugrelated stimuli in drug-experienced individuals.
\end{abstract}

Key words: AMPAR; NMDAR; metaplasticity; synaptic scaling; long-term depression; psychostimulant; addiction

\section{Introduction}

Neural circuits are thought to encode information via synaptic plasticity, a persistent upregulation or downregulation in the efficacy of excitatory synaptic transmission. Previous evidence suggests that synaptic plasticity in reward circuits is hijacked by addictive drugs to produce the pathological behaviors that characterize addiction (Hyman et al., 2006). The neural circuit that mediates these behaviors includes the nucleus accumbens (NAc). Excitatory synaptic transmission in NAc appears to be particularly important, as manipulation of NAc glutamatergic signaling controls drug-seeking behavior in animal models of addiction (Kalivas, 2004; Self et al., 2004). Medium-spiny projection neurons (MSNs), the principal cells of the NAc, contain abundant glutamatergic synapses and are known targets of longlasting molecular and cellular adaptations to addictive drugs (Nestler, 2001). However, the hypothesis that in vivo drug experience triggers persistent changes in excitatory synaptic function in NAc has not been thoroughly examined.

Previous studies indicate that repeated in vivo cocaine can reduce AMPAR EPSCs in MSNs in the NAc shell (Thomas et al., 2001). Thus, cocaine treatment has the capacity to engage endogenous synaptic plasticity mechanisms in NAc. This synaptic depression appears to play an important role in behavioral changes

Received Dec. 20, 2006; revised June 11, 2007; accepted June 11, 2007.

This work was supported by National Institute on Drug Abuse Grants R01 DA019666 (M.J.T.) and T32 DA07234 (P.E.R.) and the Whitehall Foundation (M.J.T.). We thank Drs. Marina Wolf, Peter Kalivas, Reed Carroll, and Pau Mermelstein for helpful comments on a previous version of this manuscript. We also thank Bonnie LaCroix for expert technical assistance.

Correspondence should be addressed to Dr. Mark J. Thomas, University of Minnesota, 6-145 Jackson Hall, 321 Church Street Southeast, Minneapolis, MN 55455. E-mail: tmhomas@umn.edu.

D0I:10.1523/JNEUROSCI.1859-07.2007

Copyright $\odot 2007$ Society for Neuroscience $\quad$ 0270-6474/07/277921-08\$15.00/0 caused by drugs, as a peptide that disrupts AMPAR endocytosis interferes with behavioral sensitization to amphetamine (Brebner et al., 2005). However, repeated in vivo psychostimulant exposure increases the number of dendritic spines on NAc MSNs (Robinson and Kolb, 2004), cell surface expression of AMPARs in NAc (Boudreau and Wolf, 2005), and the behavioral response to AMPA infusion into NAc (Pierce et al., 1996; Cornish and Kalivas, 2000; Suto et al., 2004). These results suggest psychostimulants may potentiate glutamatergic synapses in NAc MSNs.

How can we reconcile data supporting a potentiation with data supporting a depression? In general, studies consistent with NAc synaptic depression include a "challenge" injection of psychostimulant after a drug-free period to measure the persistence of drug-induced behavioral adaptations, whereas those consistent with synaptic potentiation do not. We hypothesize that an animal's recent history of drug experience alters the direction of plasticity at NAc excitatory synapses. Drug re-exposure during abstinence can induce relapse to drug-seeking in human addicts and animal models (Shaham et al., 2003). Thus, examination of this factor may not only unite some seemingly disparate experimental findings, but perhaps help us to understand the brain's response to relapse-inducing stimuli. To investigate this issue, we made whole-cell recordings in acute NAc brain slices from cocaine-treated mice. Based on the fact that NAc shell is an important locus of persistent cocaine-induced adaptations (Self et al., 2004) and on electrophysiological results from a previous study (Thomas et al., 2001), we performed all recordings in NAc shell neurons. We report two major findings. First, repeated cocaine exposure followed by an extended drug-free period (withdrawal) triggers a persistent potentiation of NAc excitatory synapses. Second, during extended withdrawal, an additional cocaine exposure becomes a potent stimulus for initiating NAc 
synaptic depression. This signals a dramatic switch in the direction of experience-dependent synaptic plasticity in animals with a history of cocaine exposure.

\section{Materials and Methods}

Behavior. Male C57BL/6J mice (24-28 d old) received five once-daily injections of either cocaine ( $15 \mathrm{mg} / \mathrm{kg}$, i.p.) or saline $(0.9 \% \mathrm{NaCl})$. Mice were habituated for $20 \mathrm{~min}$ in activity boxes (Applied Concepts, Ann Arbor, MI) before injection. Immediately after each injection, horizontal locomotor activity, measured as "crossovers" from one side of the box to the other, was monitored for $40 \mathrm{~min}$. In Figure $5 B$, mice in the saline- and cocaine-challenged groups were handled and injected with saline 2-4 times ( 1 per day) during the withdrawal period to mitigate any potential effects of stress during the challenge injection procedure.

Electrophysiology. Sagittal slices of the NAc shell $(240 \mu \mathrm{m})$ were prepared as described previously (Thomas et al., 2001). Slices recovered in a holding chamber for at least $1 \mathrm{~h}$ before use. During recording they were superfused with ACSF $\left(22-23^{\circ} \mathrm{C}\right)$ saturated with $95 \% \mathrm{O}_{2} / 5 \% \mathrm{CO}_{2}$ and containing (in mM) $119 \mathrm{NaCl}, 2.5 \mathrm{KCl}, 1.0 \mathrm{NaH}_{2} \mathrm{PO}_{4}, 1.3 \mathrm{MgSO}_{4}, 2.5$ $\mathrm{CaCl}_{2}, 26.2 \mathrm{NaHCO}_{3}$ and 11 glucose. Picrotoxin $(100 \mu \mathrm{M})$ was added to block $\mathrm{GABA}_{\mathrm{A}}$ receptor-mediated IPSCs. Cells were visualized using infrared-differential interference contrast optics. Medium spiny neurons were identified by their morphology and high resting membrane potential $(-75$ to $-85 \mathrm{mV})$. To assess excitatory synaptic transmission, neurons were voltage clamped at $-80 \mathrm{mV}$ using a Multiclamp 700A amplifier (Molecular Devices, Foster City, CA). Electrodes (3-5 M $\Omega$ ) contained (in $\mathrm{mm}$ ) 117 cesium gluconate, $2.8 \mathrm{NaCl}, 20$ HEPES, 0.4 EGTA, 5 tetraethylammonium-Cl, 2 MgATP, and 0.3 MgGTP, pH 7.2$7.4(285-295 \mathrm{mOsm})$. Series resistance $(10-40 \mathrm{M} \Omega)$ and input resistance were monitored on-line with a $4 \mathrm{mV}$ depolarizing step $(100 \mathrm{~ms})$ given with each afferent stimulus. Afferents were stimulated at $0.1 \mathrm{~Hz}$ by a glass monopolar microelectrode filled with ACSF and placed at the prelimbic cortex-NAc border. Data were filtered at $2 \mathrm{kHz}$, digitized at $5 \mathrm{kHz}$, and collected and analyzed using custom software (Igor Pro; Wavemetrics, Lake Oswego, OR). AMPAR/NMDAR ratios were computed from EPSCs at $+40 \mathrm{mV}$ with and without $50 \mu \mathrm{M} \mathrm{D}-\mathrm{AP}-5$ as described previously (Thomas et al., 2001). NMDAR EPSC decay time constants were calculated from averaged currents (those used to obtain AMPAR/NMDAR ratio) by fitting to double exponential equations. Weighted mean decay time constants were calculated to compare between groups (Rumbaugh and Vicini, 1999). Miniature EPSCs (>300 per cell) were collected in the presence of either tetrodotoxin $(1.5 \mu \mathrm{M})$ or lidocaine hydrochloride (0.6-0.8 mM). Dual-component mEPSCs were collected in the additional presence of $20 \mu \mathrm{M}$ glycine, in the absence of added $\mathrm{Mg}^{2+}$ and at a holding potential of $-65 \mathrm{mV}$. Quantal events were analyzed using Minianalysis software (Synaptosoft, Decatur, GA) and verified by eye. For each cell, a random stretch of 200 mEPSCs was used to construct cumulative probability plots and to calculate mean mEPSC amplitudes. Current-voltage ( $I-V)$ experiments (see Figs. $1 D, 4 B, 5 B)$ and paired-pulse experiments (see Fig. $2 D$ ) were performed in the presence of $50 \mu \mathrm{M}$ D-AP-5. Internal solution for $I-V$ experiments contained $0.1 \mathrm{~mm}$ spermine (see Fig. $1 D$ ) only holding potentials were corrected for liquid junction potential.

Statistics. In all experiments, data acquisition and analysis were performed blindly. On $>90 \%$ of recording days, a similar amount of data were collected from cocaine and saline groups. Results are presented as mean \pm SEM. Statistical significance was assessed using two-tailed Student's $t$ tests or ANOVA and Newman-Keuls post hoc tests for pairedpulse experiments (see Fig. $2 D$ ) and data presented in Figures $4 B$ and $5 B$. Traces in figures have had stimulus artifacts removed and are averages of $20-25$ consecutive responses.

\section{Results}

\section{Cocaine treatment increases synaptic strength in NAc} shell MSNs

We used a standard paradigm for cocaine treatment (five oncedaily injections of $15 \mathrm{mg} / \mathrm{kg}$, i.p.) (Fig. $1 A$ ) that produced clear behavioral sensitization ( $38.2 \pm 6.4$ vs $183.3 \pm 16.2$ crossovers on
A

Treatment cocaine or saline record

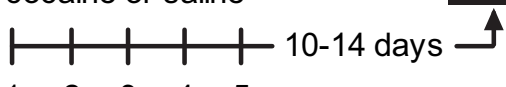

Day $\quad 1 \quad 2 \quad 3 \quad 3 \quad 4 \quad 5$
B
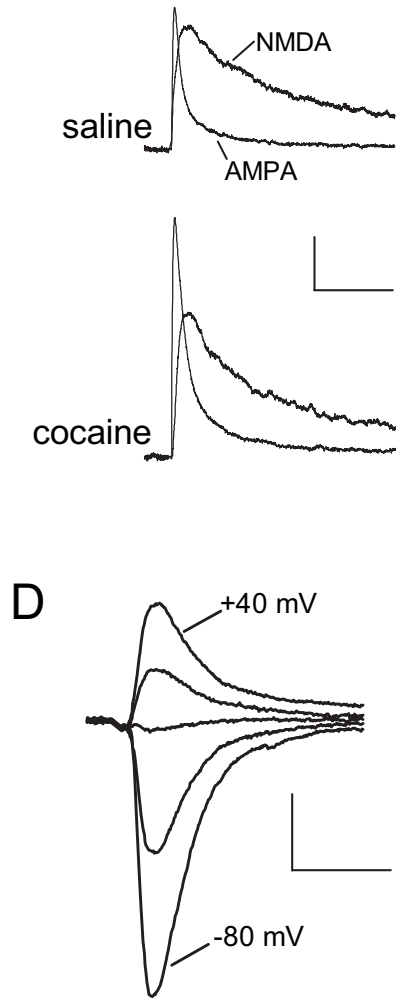

C

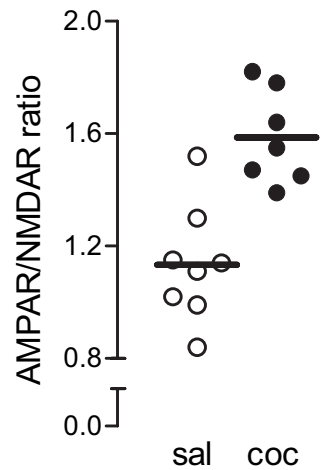

Figure 1. Repeated cocaine administration increases NAc excitatory synaptic strength. $\boldsymbol{A}$, Experimental timeline. $\boldsymbol{B}$, Sample EPSCs from saline- (sal) and cocaine-treated (coc) animals. Calibration: $100 \mathrm{~ms}, 20 \mathrm{pA}$. C, AMPAR/NMDAR ratio values from neurons in saline- (open circles; $n=8$ cells, 5 mice) and cocaine-treated mice (filled circles; $n=7$ cells, 6 mice). Hash marks indicate mean values. $\boldsymbol{D}$, Left, Examples of evoked AMPA-mediated EPSCs at membrane potentials from $-80 \mathrm{mV}$ to $+40 \mathrm{mV}$. Calibration: $50 \mathrm{pA}, 20 \mathrm{~ms}$. Right, I-V relationship for AMPAR EPSCs in saline- and cocaine-treated mice ( $n=8$ cells, 5 mice in each group). The lines represent the linear regression ( $r=0.99$ for each group). Error bars represent SEM.

days 1 vs 5 , measured in a subset of subjects; $t_{(1,28)}=8.30 ; p<$ $0.001)$. To examine long-lasting physiological effects of cocaine exposure, we prepared acute NAc brain slices from cocaine- and saline-treated mice 10-14 d after the last injection. We first measured the ratio of peak AMPAR- to peak NMDAR-mediated evoked synaptic current in whole-cell recordings from MSNs in the NAc shell. This ratio has proven to be a sensitive assay for the detection of differences in glutamatergic synaptic strength between cells in different slices from different animals (Hsia et al., 1998; Thomas et al., 2001; Ungless et al., 2001; Saal et al., 2003; Borgland et al., 2004; Dong et al., 2004; Faleiro et al., 2004; Dumont et al., 2005; Bellone and Luscher, 2006; Clem and Barth, 2006). We observed a $40 \%$ increase in the AMPAR/NMDAR ratio in cells from cocaine- versus saline-treated mice (Fig. $1 C$ ) $\left(1.58 \pm 0.06\right.$ vs $\left.1.13 \pm 0.07 ; t_{(1,13)}=4.62 ; p=0.0005\right)$.

AMPARs lacking an edited GluR2 subunit show inward rectification mediated by intracellular polyamines (Cull-Candy et al., 2006). Thus, an inclusion or exclusion of synaptic GluR2-lacking 
A

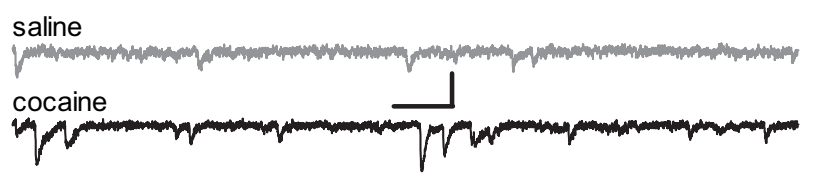

B
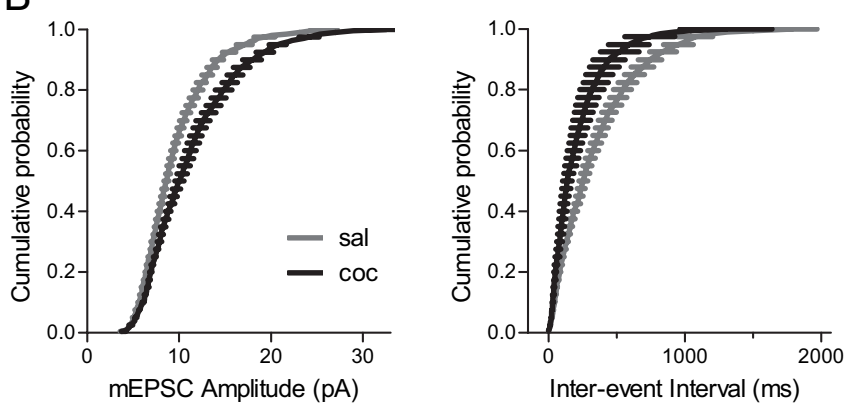

C

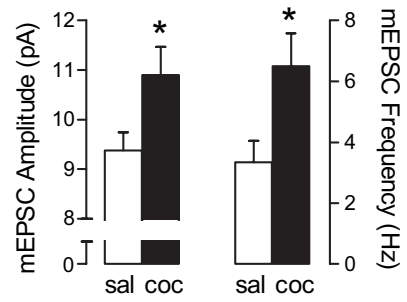

D

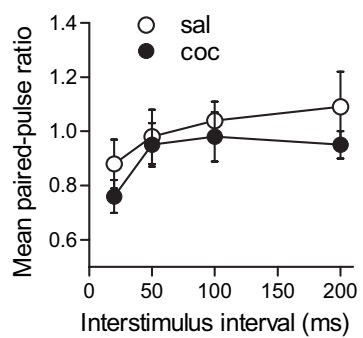

Figure 2. Repeated cocaine administration increases the amplitude and frequency of AMPAR mEPSCs without changing the paired-pulse ratio. $\boldsymbol{A}$, Sample traces of mEPSCs from neurons in saline- (sal) and cocaine-treated (coc) groups. Calibration: $100 \mathrm{~ms}, 20$ pA. B, Cumulative probability for mEPSC amplitude (left) and mEPSC interevent interval (right) obtained in saline- (gray line; $n=12$ cells, 6 mice) and cocaine-treated mice (black line; $n=7$ cells, 4 mice). $\boldsymbol{C}$, Mean values for mEPSC amplitude and frequency. ${ }^{*} p<0.05$. $D$, Mean paired-pulse ratio values in saline- ( $n=10$ cells, 6 mice) and cocaine-treated ( $n=9$ cells, 4 mice) mice are shown for different interstimulus intervals (two-way ANOVA, $F_{(1,68)}=1.907, p>0.05$ ). Error bars represent SEM.

AMPARs would be represented as a change in the AMPAR/ NMDAR ratio as measured at a positive potential. Although we pharmacologically isolated AMPAR EPSCs and provided a defined concentration of intracellular polyamines $(0.1 \mathrm{~mm}$ spermine), we did not detect a difference in either the reversal potential $(2.09 \pm 2.91 \mathrm{mV}$ for saline vs $0.85 \pm 3.77 \mathrm{mV}$ for cocaine) or the rectification index, which we measured by dividing the EPSC amplitude at $+40 \mathrm{mV}$ by the amplitude at $-80 \mathrm{mV}(0.55 \pm 0.06$ for saline and $0.54 \pm 0.06$ for cocaine) (Fig. $1 D$ ). This suggests that the cocaine-induced increase in AMPAR/NMDAR ratio does not reflect a change in the presence of GluR2-lacking AMPARs at the synapse.

\section{Cocaine treatment increases AMPAR mEPSC amplitude and frequency}

To determine the source of the AMPAR/NMDAR ratio increase in cocaine-treated mice, we recorded miniature AMPAR EPSCs (mEPSCs) in NAc MSNs. The mean amplitude distribution of quantal events in the cocaine group was shifted to the right compared with the saline group (Fig. $2 B$ ) and the mean amplitude was significantly increased (Fig. $2 C)\left(t_{(1,17)}=2.42 ; p=0.027\right)$. These results suggest that the increase in AMPAR/NMDAR ratio is attributable, at least in part, to increased AMPAR function and/or number. The frequency of mEPSCs was also increased in the cocaine group (Fig. $2 C)\left(t_{(1,17)}=2.56 ; p=0.020\right)$. A frequency increase is classically interpreted as an enhancement of presynaptic function. However, the responses to paired-pulse stimulation, a standard paradigm to test for changes in glutamate release probability $\left(p_{\mathrm{r}}\right)$, were not affected in the cocaine group (Fig. $2 D$ ), arguing against a global change in $p_{\mathrm{r}}$. The increase in mEPSC frequency could simply indicate that a larger number of events are rising above the amplitude detection threshold in the cocaine group. However, given that cocaine exposure induces new dendritic spine formation (Robinson and Kolb, 2004), our results would also be consistent with activity at these putative additional synaptic contacts.

No cocaine-induced changes in synaptic NMDAR function To test for changes in NMDAR function, we compared the mean amplitude of NMDAR-mediated mEPSCs between groups. Because of inherent difficulties in measuring "pure" NMDARmediated mEPSCS in NAc MSNs (Thomas et al., 2001), we measured a mean NMDAR mEPSC amplitude for each cell using a subtraction method. We recorded under zero- $\mathrm{Mg}^{2+}$ conditions to measure a mean dual-component $\mathrm{MEPSC}$, followed by recording in the NMDAR antagonist, D-AP-5 $(50 \mu \mathrm{M})$, to measure the mean AMPAR mEPSC. Digital subtraction of the mean AMPAR mEPSC from the mean dual component mEPSC yielded a mean NMDAR mEPSC. We did not detect a significant difference in the mean amplitude of NMDAR mEPSCs in cocaine-treated mice (Fig. $3 A)(1.93 \pm 0.24 \mathrm{mV}$ for saline vs $2.02 \pm 0.31 \mathrm{mV}$ for cocaine). The kinetics of NMDAR EPSC decay can be altered by changes in the types of NR2 subunits incorporated into synaptic NMDARs (Monyer et al., 1994); however, we found no difference between groups in this parameter (Fig. $3 B$ ) (95.8 $\pm 8.2 \mathrm{~ms}$ for saline vs $96.3 \pm 6.6 \mathrm{~ms}$ for cocaine). Thus, we are not able to detect any cocaine-induced alteration of NMDAR function and/or number.

\section{Development of cocaine-induced synaptic plasticity is a function of withdrawal duration and dosing schedule} Previous studies have identified cocaine-induced changes in NAc AMPARs and/or AMPAR involvement in cocaine sensitization that only emerge during extended withdrawal (Pierce et al., 1996; Li et al., 1997; Churchill et al., 1999; Boudreau and Wolf, 2005). To determine whether withdrawal time is a critical parameter for cocaine-induced NAc synaptic potentiation, we first examined AMPAR/NMDAR ratio in mice $24 \mathrm{~h}$ after a repeated injection paradigm $(15 \mathrm{mg} / \mathrm{kg}$ daily for $5 \mathrm{~d}$ ) (Fig. $4 A$ ). Whereas there is no significant difference between injection-naive mice and salineinjected mice, we find a significant decrease in mean AMPAR/ NMDAR ratio in cocaine-treated mice (Fig. $4 B$ ). This decrease is not accompanied by any change in the synaptic $I-V$ curve (Fig. $4 B$ ) or NMDAR decay kinetics (data not shown), arguing against widespread changes in subunit composition for synaptic AMPARs or NMDARs. This decrease in AMPAR/NMDAR ratio during early withdrawal starkly contrasts with the robust potentiation in AMPAR/NMDAR ratio observed during extended withdrawal (Fig. 1), strongly suggesting that synaptic potentiation is not present during early withdrawal, but develops as a function of the duration of withdrawal.

To understand the effect of dosing schedule on the development of cocaine-induced synaptic plasticity, we first tested the idea that a single injection of cocaine might be sufficient to induce synaptic plasticity. In ventral tegmental area dopamine neurons, for example, it is well established that a single, modest dose of cocaine $(15 \mathrm{mg} / \mathrm{kg}$, i.p.) is sufficient to induce robust synaptic 
A
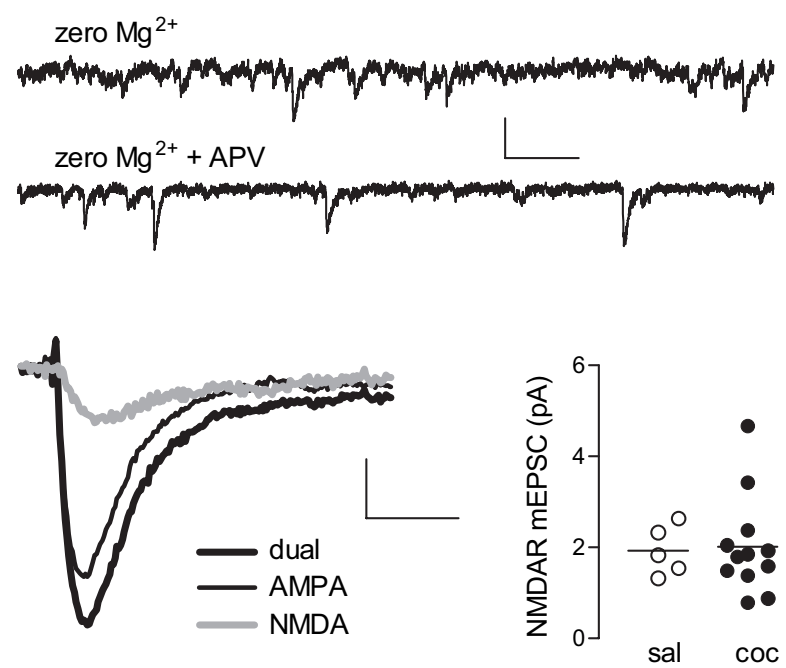

B

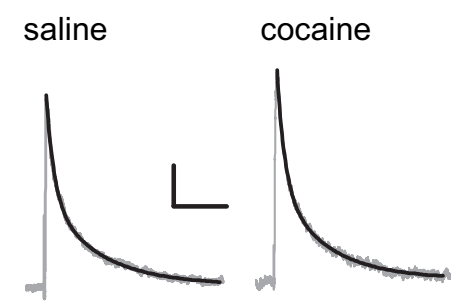

A

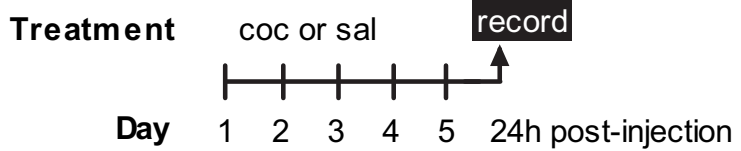

B
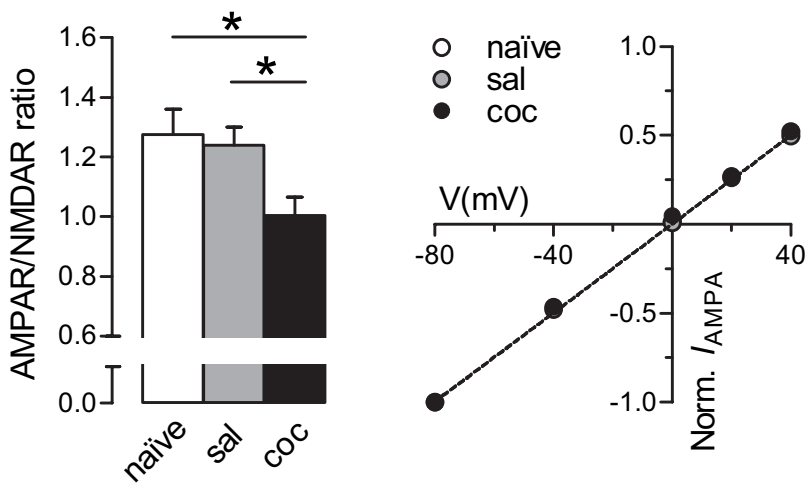

c

Figure 3. Repeated cocaine administration does not affect synaptic NMDAR function. $\boldsymbol{A}$, Top, Samples of mEPSCs recorded at $-65 \mathrm{mV}$ in zero $\mathrm{Mg}^{2+}$ solution in the absence (top) and presence (bottom) of D-APV (50 $\mu \mathrm{m})$ in a cocaine-treated mouse. Calibration: $100 \mathrm{~ms}, 20 \mathrm{pA}$. Bottom, Sample averaged traces of $\mathrm{mEPSC}$ obtained in each condition plus the subtracted trace that yielded an average NMDAR mEPSC. Calibration: $10 \mathrm{~ms}, 2$ pA. Bottom right, Mean NMDAR $\mathrm{mEPSC}$ amplitude values for individual neurons $[n=5$ cells, 4 mice for saline (sal); $n=12$ cells, 6 mice for cocaine (coc)]. Hash marks indicate group means. $\boldsymbol{B}$, Left, Sample traces of NMDAR EPSCs from saline- and cocaine-treated mice (in gray) are shown with a superimposed double exponential curve (in black). Calibration: $500 \mathrm{~ms}, 20 \mathrm{pA}$. Right, Weighted decay time constant $\left(\tau_{\mathrm{w}}\right)$ values of evoked NMDAR EPSCs from saline- ( $n=8$ cells, 5 mice) and cocaine-treated ( $n=$ 7 cells, 6 mice) mice. Hash marks indicate group means. Error bars represent SEM.

potentiation (Ungless et al., 2001). We found that neither a single injection of $15 \mathrm{mg} / \mathrm{kg}$ cocaine nor $40 \mathrm{mg} / \mathrm{kg}$ cocaine (the highest dose which does not induce seizures, in our hands) induced any change in the mean AMPAR/NMDAR ratio after $24 \mathrm{~h}$ of withdrawal (Fig. 4D), suggesting that these treatments do not induce synaptic plasticity in NAc during early withdrawal. Given the time dependence for the emergence of NAc synaptic potentiation with repeated cocaine, we also tested whether a single $40 \mathrm{mg} / \mathrm{kg}$ injection would produce potentiation after $7 \mathrm{~d}$ of withdrawal. We did not observe any significant difference at this time point either (Fig. 4D). Together, these data suggest that a single cocaine injection is not sufficient to induce synaptic plasticity in NAc MSNs. Thus, both the duration of drug withdrawal and the dosing schedule are important factors in the induction and the direction of this synaptic plasticity.

Cocaine history determines the direction of cocaine-induced synaptic plasticity

In human addicts and animal models, a single drug exposure in drug-experienced individuals can reinstate drug-seeking behavior, even after a protracted drug-free period (Shaham et al.,

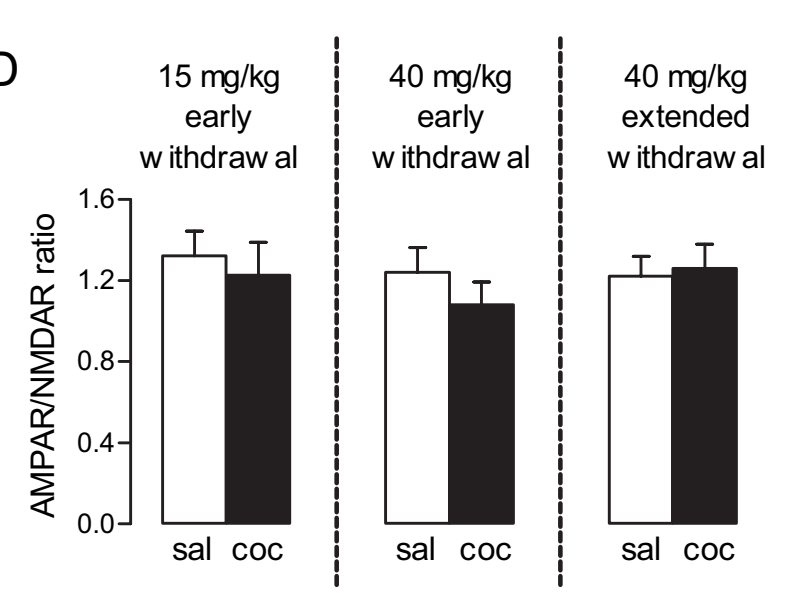

sal $\operatorname{coc}$

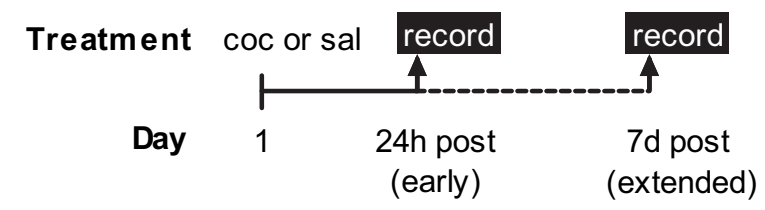

Figure 4. Cocaine-induced NAc synaptic potentiation is absent during early withdrawal and does not develop after a single cocaine exposure. $\boldsymbol{A}$, Timeline for experiments in $\boldsymbol{B}$. $\boldsymbol{B}$, Left, Mean AMPAR/NMDAR ratio from naive mice ( $n=16$ cells, 5 mice), saline-treated mice (sal; $n=18$ cells, 5 mice), and cocaine-treated mice (coc; $n=21$ cells, 6 mice; ANOVA, $F_{(2,53)}=$ $4.843, p=0.012$; Student-Newman-Keuls post hoc test, $\left.{ }^{*} p<0.05\right)$. Right, $I-V$ relationship for AMPAR EPSCs in naive, saline-treated, and cocaine-treated mice. The lines represent the linear regression ( $r=0.99$ for each group). C, Timeline for experiments in $\boldsymbol{D}$. D, Left, Mean AMPAR/NMDAR ratio from saline- and cocaine-treated mice $(15 \mathrm{mg} / \mathrm{kg}$ early withdrawal, $n=$ 6 cells, 4 mice in each group; $40 \mathrm{mg} / \mathrm{kg}$ early withdrawal, $n=11$ cells, 6 mice for saline and $n=$ 7 cells, 4 mice for cocaine; $40 \mathrm{mg} / \mathrm{kg}$ extended withdrawal, $n=11$ cells, 5 mice for saline and $n=12$ cells, 5 mice for cocaine). Error bars represent SEM.

2003). Manipulations of NAc glutamate signaling exert powerful control over reinstatement of drug-seeking as well as the expression of behavioral sensitization to cocaine (Kalivas, 2004). Thus, we hypothesized that experience-elicited plasticity of NAc glutamatergic synapses may be differentially engaged by cocaine reexposure in cocaine-experienced versus drug-naive mice. After repeated cocaine injection and $10-14 \mathrm{~d}$ of withdrawal, mice were either left undisturbed (no challenge) or injected with saline or 
A

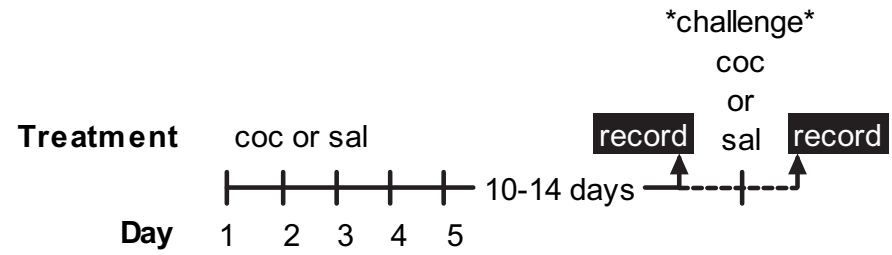

B
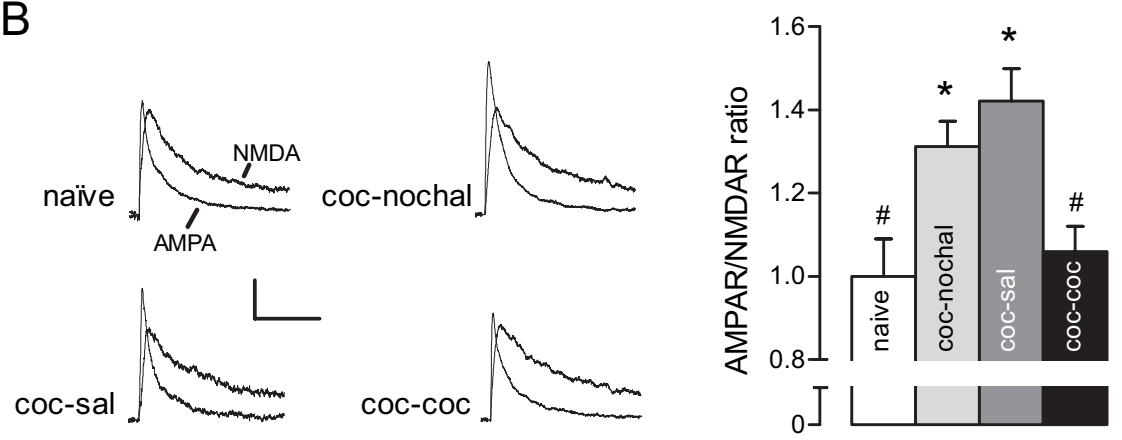

Treatment -- $\operatorname{coc} \operatorname{coc} \operatorname{coc}$ Challenge -- -- sal coc

C

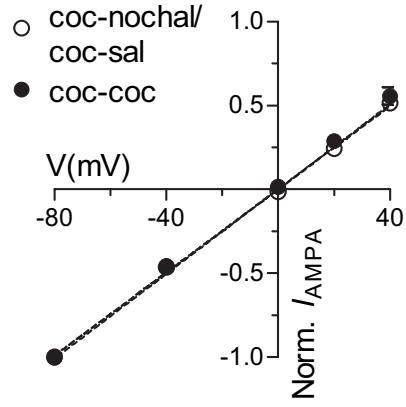

$\mathrm{D}$

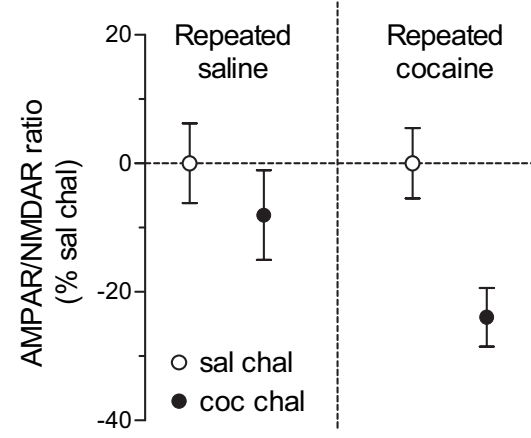

Figure 5. Cocaine exposure history determines whether NAc excitatory synapses exhibit potentiation or depression. $\boldsymbol{A}$, Experimental timeline. $\boldsymbol{B}$, Left, Sample EPSCs from naive and cocaine-treated mice. Calibration: $100 \mathrm{~ms}, 20$ pA. Right, Mean AMPAR/ NMDAR ratio in naive ( $n=6$ cells, 3 mice), coc-nochal (coc treatment with no challenge; $n=8$ cells, 5 mice), coc-sal (coc treatment with sal challenge; $n=11$ cells, 6 mice), and coc-coc (coctreatment with coc challenge; $n=13$ cells, 6 mice) groups. \#Significantly different from each bar labeled with an asterisk (ANOVA, $F_{(3,29)}=8.167, p=0.0004$; Student-Newman-Keuls post hoc test, $p<0.05)$. C, I-V relationship for AMPAR EPSCs in coc-nochal/coc-sal and coc-coc mice. Data from coc-nochal and coc-sal have been pooled because there is no significant difference between groups. The lines represent the linear regression $(r=$ 0.99 for each group). $\boldsymbol{D}$, Summary graph indicating percentage decrease of AMPAR/NMDAR ratio in cocaine-challenged mice relative to saline-challenged controls. Animals that had no previous drug experience (repeated saline; $n=13$ cells, 6 mice for saline challenge, and $n=7$ cells, 5 mice for cocaine challenge) showed no significant depression. Drug-experienced animals (coc-coc vs coc-sal; normalized to coc-sal) exhibited significant depression. Error bars represent SEM.

cocaine $24 \mathrm{~h}$ before electrophysiological study. Consistent with our previous experiment (Figs. 1, 2), we find that repeated cocaine treatment followed by extended withdrawal results in robust synaptic potentiation relative to an experimentally naive control group (Fig. 5B). However, this new potentiated baseline level of AMPAR-mediated transmission is reversed by a single additional cocaine injection but not by saline (Fig. $5 B$ ). This indicates that the cocaine history specifically altered the response to cocaine re-exposure. Previous work has demonstrated that this cocaine-induced decrease in AMPAR/NMDAR ratio reflects a reduction in AMPAR function and/or number, and was not associated with any detectable change in NMDAR function and/or number (Thomas et al., 2001). Here, we report the additional findings that this AMPAR/NMDAR ratio decrease in the cocainechallenged group is not accompanied by any change in the AM-
PAR EPSC $I-V$ relationship (Fig. $5 C$ ), nor any change in decay time constants of synaptic NMDARs (data not shown).

In contrast to drug-experienced mice, a single cocaine injection in drug-naive mice (i.e., mice that received repeated saline injections according to the schedule in Fig. $5 A$ ) did not induce any significant change in the AMPAR/NMDAR ratio (1.49 \pm 0.093 for saline and $1.38 \pm 0.105$ for cocaine; $\left.t_{(1,18)}=0.788 ; p=0.441\right)$ (Fig. $5 D$ ). These data are summarized in Figure $5 D$, with values for cocaine-challenged animals normalized to saline-challenged controls. These results demonstrate the ability of a single cocaine exposure to differentially modify glutamatergic synaptic strength on NAc MSNs in drug-experienced versus drug-naive animals.

\section{Discussion}

Our results indicate that in vivo cocaine exerts dynamic bidirectional control over excitatory synaptic strength in NAc, a structure known for its involvement in producing drug-seeking behavior. These data provide direct evidence of experiencedependent changes in NAc synaptic strength, little of which has been collected to date. Several previous studies have demonstrated that cocaine exposure can alter the capacity of NAc synapses to undergo synaptic plasticity that is triggered by the experimenter (Fourgeaud et al., 2004; Yao et al., 2004; Goto and Grace, 2005; Martin et al., 2006). In general, however, these studies were not purposefully designed to assess whether NAc synaptic strength is modified directly by cocaine experience. Thus, this issue has remained open for speculation. Our data add to a growing body of evidence that cocaine experience drives endogenous synaptic plasticity in the mesolimbic dopamine system.

We find that cocaine experience produces a potentiation that develops during drug withdrawal, and an abrupt depression that follows a single drug re-exposure. Thus, repeated in vivo cocaine establishes a new elevated baseline level of excitatory synaptic transmission in the NAc and converts a cocaine injection, an ineffective stimulus in drug-naive mice, into a potent stimulus for synaptic depression. This information may unify interpretations of intriguing results which had seemed mutually incompatible. For example, extended withdrawal from repeated cocaine exposure increases cell-surface expression of AMPAR subunits in NAc tissue (Boudreau and Wolf, 2005) as well as dendritic spine density in NAc MSNs (Robinson and Kolb, 2004), both of which are consistent with a synaptic potentiation. However, in studies where cocaine withdrawal was interrupted by cocaine re-exposure $1 \mathrm{~d}$ before sampling, AMPAR-mediated mEPSCs in NAc MSNs were attenuated and the induction of in vitro long-term depression was occluded (Thomas et al., 2001). Our present results indicate that 
a single additional cocaine exposure in drug-experienced animals can determine whether NAc glutamatergic synapses exhibit depression or potentiation.

\section{Cocaine experience-elicited synaptic potentiation in NAc}

A possible mechanism for the potentiation is suggested by an intriguing line of experiments by Wolf et al. (2004) examining AMPAR surface expression in cultured NAc neurons. In these experiments, transient activation of dopamine receptors increases surface-level AMPARs. This raises the possibility that in vivo, the transient activation of dopamine receptors during cocaine exposure may increase NAc AMPAR surface levels and enhance EPSCs. However, the story is not likely to be so straightforward. For example, dopamine receptor activation inhibits AMPAR EPSCs in NAc slices (Nicola et al., 2000), an effect that is enhanced with repeated cocaine administration (Beurrier and Malenka, 2002). Furthermore, the day after discontinuing repeated cocaine injections, neither the synaptic potentiation (Fig. $4 B$ ) nor the increased level of surface AMPARs (Boudreau and Wolf, 2005) is present. The fact that the potentiation takes time to develop during withdrawal suggests it is not directly related to the ability of dopamine receptor activation to drive AMPAR insertion into the membrane.

Another possible mechanism for the potentiation is homeostatic synaptic scaling: an alteration in synaptic responses throughout a cell that compensates for chronic changes in activity (Turrigiano and Nelson, 2004). For example, by suppressing activity in visual cortex through visual deprivation, AMPAR EPSCs can be upregulated in a cell-wide manner (Desai et al., 2002). Repeated in vivo cocaine is known to reduce intrinsic excitability of NAc MSNs (Zhang et al., 1998; Hu et al., 2004; Dong et al., 2006). Thus, decreased excitability after drug cessation could trigger synaptic scaling mechanisms to augment excitatory synaptic strength. Another possibility, raised by Boudreau and Wolf (2005), is that the decreased levels of extracellular glutamate known to occur in NAc after repeated cocaine (Pierce et al., 1996; Baker et al., 2003) may engage synaptic scaling. However it may be triggered, the scaling phenomenon typically involves changes in number (as opposed to purely changes in function) of synaptic AMPARs (Turrigiano and Nelson, 2004). Cocaine-elicited synaptic potentiation in NAc appears to be consistent with this mechanism. For example, repeated cocaine exposure increases surface expression of AMPARs, a portion of which are associated with synapses (Boudreau and Wolf, 2005).

The functional significance of cocaine-induced NAc synaptic potentiation is not yet clear. However, viral vector-mediated overexpression of AMPAR subunits in NAc is sufficient to modify reward-related behaviors such as cocaine conditioned-place preference (Kelz et al., 1999) intracranial self-stimulation (Todtenkopf et al., 2006), and stress-induced reinstatement of cocaine-seeking behavior (Sutton et al., 2003). Once we understand the degree to which this overexpression can artificially potentiate excitatory synaptic strength on MSNs, we will have a framework within which to understand how cocaine-induced changes in NAc synaptic strength can affect behavioral output of reward circuits.

\section{Cocaine experience-induced metaplasticity?}

A single cocaine injection in drug-experienced animals during an extended drug-free period triggers a synaptic depression whereas the same treatment in drug-naive animals does not. Thus, repeated cocaine dramatically alters an animal's response to subsequent cocaine during extended withdrawal. This type of shift has been referred to as metaplasticity, a condition in which the history of activity in a given neuron or synapse alters the magnitude or direction of plasticity in response to subsequent stimulation (Abraham and Bear, 1996; Bear, 2003). A compelling example of metaplasticity comes from visual deprivation experiments. Reduction in activity of visual cortical neurons can shift the response of these neurons to a given evoked stimulus from longterm depression to long-term potentiation (LTP) (Kirkwood et al., 1996; Bear, 2003). As in other forms of metaplasticity, repeated cocaine experience appears to shift the threshold necessary for generating a plastic response, in this case, synaptic depression. Our data indicate that multiple cocaine exposures are necessary to decrease the AMPAR/NMDAR ratio in mice that had previously been drug-naive. However, a single cocaine reexposure is sufficient for NAc synaptic depression in drugexperienced, "abstinent" mice. Although the degree of overlap in the mechanisms for any synaptic depression elicited under these two conditions will require additional study, it is clear that cocaine experience and withdrawal lowers the threshold (i.e., the number of drug exposures necessary) for cocaine-induced NAc synaptic depression.

What are potential mechanisms for this threshold shift? In visual cortical metaplasticity, changes in the subunit composition of synaptic NMDARs, an enhanced inclusion of NR2Bcontaining receptors, prolong calcium entry and facilitate LTP induction (Quinlan et al., 1999a,b; Philpot et al., 2001). NR2B expression in NAc is reported to be decreased at $24 \mathrm{~h}$ after repeated cocaine and increased after 2 weeks of withdrawal (Loftis and Janowsky, 2000). Thus, we examined NMDAR EPSC decay kinetics, an indicator for addition or loss of synaptic NR2Bcontaining receptors (Monyer et al., 1994; Vicini et al., 1998; Rumbaugh and Vicini, 1999; Schilstrom et al., 2006). We did not observe any changes in this parameter. This does not rule out a potential change in NR2B-containing receptors that are extrasynaptic (van Zundert et al., 2004; Kohr, 2006). However, the lack of change in NMDAR EPSC decay kinetics strongly suggests that the mechanism for cocaine-induced metaplasticity is not directly shared with other known forms of in vivo metaplasticity.

Another possible mechanism for the reduced synaptic depression threshold is suggested by the fact that cocaine treatment enhances NAc glutamate release after cocaine re-exposure during extended withdrawal (Pierce et al., 1996; Reid and Berger, 1996). Coupled with our finding of enhanced AMPAR EPSCs, this suggests cocaine re-exposure in cocaine-treated animals triggers supraphysiological activation of NAc glutamate transmission. Intense glutamate signaling can induce AMPAR endocytosis and synaptic depression in vitro, most commonly through prolonged NMDAR activation (Carroll et al., 1999; Beattie et al., 2000; Mangiavacchi and Wolf, 2004). The involvement of AMPAR endocytosis in the synaptic depression described here seems a likely possibility. For example, the delivery of an AMPAR-endocytosisblocking peptide into NAc interfered with the expression of behavioral sensitization to amphetamine (Brebner et al., 2005). These results offer potential clues to the mechanism of cocaineelicited NAc synaptic depression. They also suggest that this depression is a key factor in long-lasting behavioral modification by addictive drug exposure.

\section{Conclusion}

Our results define prominent features of cocaine-induced synaptic plasticity in a key neural circuit for reward and drug-seeking behavior. An important future direction will be to determine whether these alterations may be pathogenic mediators that con- 
tribute to addiction, or perhaps homeostatic adaptations that counteract it. For example, the increase in NAc synaptic efficacy measured here may be a balancing factor against deleterious adaptations, in which case its reversal during a drug re-exposure may gate a signal for drug-seeking behavior. There is increasing evidence that inhibition of NAc MSNs (GABAergic projection neurons) promotes reward-seeking behavior (Kelley, 2004; Taha and Fields, 2006), perhaps by disinhibiting "downstream" regions such as the ventral pallidum (McFarland and Kalivas, 2001; Tindell et al., 2005) and lateral hypothalamus (Harris et al., 2005). Understanding the role of cocaine-induced NAc synaptic plasticity in addiction will require detailed examination of this phenomenon in relationship to animal behavior in models of addiction. The present results should help bridge the divide between our rapidly expanding knowledge base of molecular neuroadaptations to cocaine and the reorganization of brain reward circuits that results in addiction.

\section{References}

Abraham WC, Bear MF (1996) Metaplasticity: the plasticity of synaptic plasticity. Trends Neurosci 19:126-130.

Baker DA, McFarland K, Lake RW, Shen H, Tang XC, Toda S, Kalivas PW (2003) Neuroadaptations in cystine-glutamate exchange underlie cocaine relapse. Nat Neurosci 6:743-749.

Bear MF (2003) Bidirectional synaptic plasticity: from theory to reality. Philos Trans R Soc Lond B Biol Sci 358:649-655.

Beattie EC, Carroll RC, Yu X, Morishita W, Yasuda H, von Zastrow M, Malenka RC (2000) Regulation of AMPA receptor endocytosis by a signaling mechanism shared with LTD. Nat Neurosci 3:1291-1300.

Bellone C, Luscher C (2006) Cocaine triggered AMPA receptor redistribution is reversed in vivo by mGluR-dependent long-term depression. Nat Neurosci 9:636-641.

Beurrier C, Malenka RC (2002) Enhanced inhibition of synaptic transmission by dopamine in the nucleus accumbens during behavioral sensitization to cocaine. J Neurosci 22:5817-5822.

Borgland SL, Malenka RC, Bonci A (2004) Acute and chronic cocaineinduced potentiation of synaptic strength in the ventral tegmental area: electrophysiological and behavioral correlates in individual rats. J Neurosci 24:7482-7490.

Boudreau AC, Wolf ME (2005) Behavioral sensitization to cocaine is associated with increased AMPA receptor surface expression in the nucleus accumbens. J Neurosci 25:9144-9151.

Brebner K, Wong TP, Liu L, Liu Y, Campsall P, Gray S, Phelps L, Phillips AG, Wang YT (2005) Nucleus accumbens long-term depression and the expression of behavioral sensitization. Science 310:1340-1343.

Carroll RC, Beattie EC, Xia H, Luscher C, Altschuler Y, Nicoll RA, Malenka RC, von Zastrow M (1999) Dynamin-dependent endocytosis of ionotropic glutamate receptors. Proc Natl Acad Sci USA 96:14112-14117.

Churchill L, Swanson CJ, Urbina M, Kalivas PW (1999) Repeated cocaine alters glutamate receptor subunit levels in the nucleus accumbens and ventral tegmental area of rats that develop behavioral sensitization. J Neurochem 72:2397-2403.

Clem RL, Barth A (2006) Pathway-specific trafficking of native AMPARs by in vivo experience. Neuron 49:663-670.

Cornish JL, Kalivas PW (2000) Glutamate transmission in the nucleus accumbens mediates relapse in cocaine addiction. J Neurosci 20:RC89.

Cull-Candy S, Kelly L, Farrant M (2006) Regulation of $\mathrm{Ca}^{2+}$-permeable AMPA receptors: synaptic plasticity and beyond. Curr Opin Neurobiol 16:288-297.

Desai NS, Cudmore RH, Nelson SB, Turrigiano GG (2002) Critical periods for experience-dependent synaptic scaling in visual cortex. Nat Neurosci 5:783-789.

Dong Y, Saal D, Thomas M, Faust R, Bonci A, Robinson T, Malenka RC (2004) Cocaine-induced potentiation of synaptic strength in dopamine neurons: behavioral correlates in GluRA $(-/-)$ mice. Proc Natl Acad Sci USA 101:14282-14287.

Dong Y, Green T, Saal D, Marie H, Neve R, Nestler EJ, Malenka RC (2006) CREB modulates excitability of nucleus accumbens neurons. Nat Neurosci 9:475-477.

Dumont EC, Mark GP, Mader S, Williams JT (2005) Self-administration enhances excitatory synaptic transmission in the bed nucleus of the stria terminalis. Nat Neurosci 8:413-414.

Faleiro LJ, Jones S, Kauer JA (2004) Rapid synaptic plasticity of glutamatergic synapses on dopamine neurons in the ventral tegmental area in response to acute amphetamine injection. Neuropsychopharmacology 29:2115-2125.

Fourgeaud L, Mato S, Bouchet D, Hemar A, Worley PF, Manzoni OJ (2004) A single in vivo exposure to cocaine abolishes endocannabinoidmediated long-term depression in the nucleus accumbens. J Neurosci 24:6939-6945.

Goto Y, Grace AA (2005) Dopamine-dependent interactions between limbic and prefrontal cortical plasticity in the nucleus accumbens: disruption by cocaine sensitization. Neuron 47:255-266.

Harris GC, Wimmer M, Aston-Jones G (2005) A role for lateral hypothalamic orexin neurons in reward seeking. Nature 437:556-559.

Hsia AY, Malenka RC, Nicoll RA (1998) Development of excitatory circuitry in the hippocampus. J Neurophysiol 79:2013-2024.

Hu XT, Basu S, White FJ (2004) Repeated cocaine administration suppresses HVA-Ca ${ }^{2+}$ potentials and enhances activity of $\mathrm{K}+$ channels in rat nucleus accumbens neurons. J Neurophysiol 92:1597-1607.

Hyman SE, Malenka RC, Nestler EJ (2006) Neural mechanisms of addiction: the role of reward-related learning and memory. Annu Rev Neurosci 29:565-598.

Kalivas PW (2004) Glutamate systems in cocaine addiction. Curr Opin Pharmacol 4:23-29.

Kelley AE (2004) Ventral striatal control of appetitive motivation: role in ingestive behavior and reward-related learning. Neurosci Biobehav Rev 27:765-776.

Kelz MB, Chen J, Carlezon Jr WA, Whisler K, Gilden L, Beckmann AM, Steffen C, Zhang YJ, Marotti L, Self DW, Tkatch T, Baranauskas G, Surmeier DJ, Neve RL, Duman RS, Picciotto MR, Nestler EJ (1999) Expression of the transcription factor deltaFosB in the brain controls sensitivity to cocaine. Nature 401:272-276.

Kirkwood A, Rioult MC, Bear MF (1996) Experience-dependent modification of synaptic plasticity in visual cortex. Nature 381:526-528.

Kohr G (2006) NMDA receptor function: subunit composition versus spatial distribution. Cell Tissue Res 326:439-446.

Li Y, Vartanian AJ, White FJ, Xue CJ, Wolf ME (1997) Effects of the AMPA receptor antagonist NBQX on the development and expression of behavioral sensitization to cocaine and amphetamine. Psychopharmacology (Berl) 134:266-276.

Loftis JM, Janowsky A (2000) Regulation of NMDA receptor subunits and nitric oxide synthase expression during cocaine withdrawal. J Neurochem 75:2040-2050.

Mangiavacchi S, Wolf ME (2004) Stimulation of $N$-methyl-D-aspartate receptors, AMPA receptors or metabotropic glutamate receptors leads to rapid internalization of AMPA receptors in cultured nucleus accumbens neurons. Eur J Neurosci 20:649-657.

Martin M, Chen BT, Hopf FW, Bowers MS, Bonci A (2006) Cocaine selfadministration selectively abolishes LTD in the core of the nucleus accumbens. Nat Neurosci 9:868-869.

McFarland K, Kalivas PW (2001) The circuitry mediating cocaine-induced reinstatement of drug-seeking behavior. J Neurosci 21:8655-8663.

Monyer H, Burnashev N, Laurie DJ, Sakmann B, Seeburg PH (1994) Developmental and regional expression in the rat brain and functional properties of four NMDA receptors. Neuron 12:529-540.

Nestler EJ (2001) Molecular basis of long-term plasticity underlying addiction. Nat Rev Neurosci 2:119-128.

Nicola SM, Surmeier J, Malenka RC (2000) Dopaminergic modulation of neuronal excitability in the striatum and nucleus accumbens. Annu Rev Neurosci 23:185-215.

Philpot BD, Sekhar AK, Shouval HZ, Bear MF (2001) Visual experience and deprivation bidirectionally modify the composition and function of NMDA receptors in visual cortex. Neuron 29:157-169.

Pierce RC, Bell K, Duffy P, Kalivas PW (1996) Repeated cocaine augments excitatory amino acid transmission in the nucleus accumbens only in rats having developed behavioral sensitization. J Neurosci 16:1550-1560.

Quinlan EM, Philpot BD, Huganir RL, Bear MF (1999a) Rapid, experiencedependent expression of synaptic NMDA receptors in visual cortex in vivo. Nat Neurosci 2:352-357.

Quinlan EM, Olstein DH, Bear MF (1999b) Bidirectional, experiencedependent regulation of $\mathrm{N}$-methyl-D-aspartate receptor subunit compo- 
sition in the rat visual cortex during postnatal development. Proc Natl Acad Sci USA 96:12876-12880.

Reid MS, Berger SP (1996) Evidence for sensitization of cocaine-induced nucleus accumbens glutamate release. NeuroReport 7:1325-1329.

Robinson TE, Kolb B (2004) Structural plasticity associated with exposure to drugs of abuse. Neuropharmacology 47 [Suppl 1]:33-46.

Rumbaugh G, Vicini S (1999) Distinct synaptic and extrasynaptic NMDA receptors in developing cerebellar granule neurons. J Neurosci 19:10603-10610.

Saal D, Dong Y, Bonci A, Malenka RC (2003) Drugs of abuse and stress trigger a common synaptic adaptation in dopamine neurons. Neuron 37:577-582.

Schilstrom B, Yaka R, Argilli E, Suvarna N, Schumann J, Chen BT, Carman M, Singh V, Mailliard WS, Ron D, Bonci A (2006) Cocaine enhances NMDA receptor-mediated currents in ventral tegmental area cells via dopamine D5 receptor-dependent redistribution of NMDA receptors. J Neurosci 26:8549-8558.

Self DW, Choi KH, Simmons D, Walker JR, Smagula CS (2004) Extinction training regulates neuroadaptive responses to withdrawal from chronic cocaine self-administration. Learn Mem 11:648-657.

Shaham Y, Shalev U, Lu L, De Wit H, Stewart J (2003) The reinstatement model of drug relapse: history, methodology and major findings. Psychopharmacology (Berl) 168:3-20.

Suto N, Tanabe LM, Austin JD, Creekmore E, Pham CT, Vezina P (2004) Previous exposure to psychostimulants enhances the reinstatement of cocaine seeking by nucleus accumbens AMPA. Neuropsychopharmacology 29:2149-2159.

Sutton MA, Schmidt EF, Choi KH, Schad CA, Whisler K, Simmons D, Karanian DA, Monteggia LM, Neve RL, Self DW (2003) Extinction-induced upregulation in AMPA receptors reduces cocaine-seeking behaviour. $\mathrm{Na}$ ture $421: 70-75$.
Taha SA, Fields HL (2006) Inhibitions of nucleus accumbens neurons encode a gating signal for reward-directed behavior. J Neurosci 26:217-222.

Thomas MJ, Beurrier C, Bonci A, Malenka RC (2001) Long-term depression in the nucleus accumbens: a neural correlate of behavioral sensitization to cocaine. Nat Neurosci 4:1217-1223.

Tindell AJ, Berridge KC, Zhang J, Pecina S, Aldridge JW (2005) Ventral pallidal neurons code incentive motivation: amplification by mesolimbic sensitization and amphetamine. Eur J Neurosci 22:2617-2634.

Todtenkopf MS, Parsegian A, Naydenov A, Neve RL, Konradi C, Carlezon Jr WA (2006) Brain reward regulated by AMPA receptor subunits in nucleus accumbens shell. J Neurosci 26:11665-11669.

Turrigiano GG, Nelson SB (2004) Homeostatic plasticity in the developing nervous system. Nat Rev Neurosci 5:97-107.

Ungless MA, Whistler JL, Malenka RC, Bonci A (2001) Single cocaine exposure in vivo induces long-term potentiation in dopamine neurons. Nature 411:583-587.

van Zundert B, Yoshii A, Constantine-Paton M (2004) Receptor compartmentalization and trafficking at glutamate synapses: a developmental proposal. Trends Neurosci 27:428-437.

Vicini S, Wang JF, Li JH, Zhu WJ, Wang YH, Luo JH, Wolfe BB, Grayson DR (1998) Functional and pharmacological differences between recombinant $N$-methyl-D-aspartate receptors. J Neurophysiol 79:555-566.

Wolf ME, Sun X, Mangiavacchi S, Chao SZ (2004) Psychomotor stimulants and neuronal plasticity. Neuropharmacology 47 [Suppl 1]:61-79.

Yao WD, Gainetdinov RR, Arbuckle MI, Sotnikova TD, Cyr M, Beaulieu JM, Torres GE, Grant SG, Caron MG (2004) Identification of PSD-95 as a regulator of dopamine-mediated synaptic and behavioral plasticity. Neuron 41:625-638.

Zhang XF, Hu XT, White FJ (1998) Whole-cell plasticity in cocaine withdrawal: reduced sodium currents in nucleus accumbens neurons. J Neurosci 18:488-498. 